\title{
Nutrition and Renal Osteodystrophy
}

\author{
Hirotoshi MORII, ${ }^{1}$ Yoshiki NISHIZAWA, ${ }^{1}$ Takami MIKI, ${ }^{1}$ \\ Yasuo OHNISHI, ${ }^{1}$ Yasuyuki OKUI, ${ }^{1}$ Gyeongbu SONG, ${ }^{1}$ \\ Kazuhiko YUKIOKA, ${ }^{1}$ Kiichiro KIKUNAMI, ${ }^{2}$ \\ Yoshiki MATSUSHITA, ${ }^{2}$ and Takashi INOUE ${ }^{2}$ \\ ${ }^{1}$ Second Department of Internal Medicine, Osaka City University, Osaka 545, Japan \\ ${ }^{2}$ Inoue Hospital, Suita 565, Japan
}

There are many factors which are related to the pathogenesis of renal osteodystrophy. Among those, nutritional factors would also be very important. Calcium, phosphate, protein, fat and calorie intake may influence the pathogenesis of renal osteodystrophy. However, there have been no definite conclusions as to what roles these nutrients may play. In the present study, firstly, it was investigated whether the efficacy of active vitamin $\mathbf{D}$ in the treatment of renal osteodystrophy was influenced by the levels of intakes of nutrients.

Secondly, the influence of diabetes mellitus on renal osteodystrophy was studied in patients with diabetic nephropathy from the standpoint of view of the control status of diabetes mellitus.

\section{Patients and Methods}

For the first study there were 63 patients with chronic renal failure, probably due to chronic glomerulonephritis under regular hemodialysis. Patients were treated with $1 \alpha$-hydroxycholecalciferol $\left(1 \alpha \mathrm{OHD}_{3}\right)$ for longer than a year. The indications for the use of $1 \alpha \mathrm{OHD}_{3}$ were hypocalcemia, elevated alkaline phosphatase(AP), bone changes noted by X-ray films and bone pain. However, for the present study, 2 groups were classified, according to the effect of the active vitamin D on the changes in serum AP and calcium. In group A (25 males and 18 females) serum AP was normalized with the daily maintenance dose of 1.0 $\mu \mathrm{g}$. In group B (12 males and 8 females) the elevated serum AP did not decrease, hypocalcemia was not normalized, or partial parathyroidectomy was performed because bone changes progressed in spite of the conservative treatment.

The average intake of nutrients during 3 days were calculated from the Table of Food Contents in Japan.

There were 23 hemodialysed patients with diabetic nephropathy (17 males and 6 females). For assessing bone changes in these patients, the clavicular score $(d / D)$ was calculated by measuring the width of the upper cortex $(d)$ and the transverse width $(D)$ of the clavicula in the posterioranterior X-ray film of the chest. The degree of subperiosteal resorption of finger bones, and the resorption of the lamina dura and the trabecular pattern of mandibular bones were investigated. The latter changes were classified into 3 groups depending on the grade.

Results

1. Correlation between the response to active vitamin $D$ and intake of nutrients. Body weight in group A was $48.7 \pm 8.3 \mathrm{~kg}$ for females $(n=18)$ and $56.3 \pm 7.6 \mathrm{~kg}$ for males $(n=25)$, and that in group B $48.2 \pm 3.7 \mathrm{~kg}$ for females $(n=8)$ and $56.0 \pm$ $6.9 \mathrm{~kg}$ for males $(n=12)$. No significant differences were demonstrated between these groups, regarding both sexes, respectively.

Significant differences were demonstrated in the intake of calcium $(p<0.05)$, fat $(p<0.05)$ and calorie $(p<0.025)$ (Table 1). In both $\mathrm{A}$ and $\mathrm{B}$ groups, intakes of calorie, protein, calcium, phosphate and fat were higher in males than in females, but these differences were not significant. Regarding calcium intake, that of the females in A group $(494 \pm 102 \mathrm{mg} / \mathrm{day}, n=11)$ was significantly higher than that in females of B group $(347 \pm 48 \mathrm{mg} / \mathrm{day}$, $n=6)(p<0.01)$. However, in males, no significant difference was demonstrated in the intake of calcium between A group $(465 \pm 129 \mathrm{mg} /$ day, $n=11)$ 
Table 1. Comparison of nutrients intake between groups A and B.

\begin{tabular}{lccc}
\hline \multirow{1}{*}{\multicolumn{1}{c}{ day }} & \multicolumn{3}{c}{ Group } \\
\cline { 2 - 4 } & $\mathrm{A}(n=20)$ & $\mathrm{B}(n=13)$ & $p$ \\
\hline Calcium (mg) & $481 \pm 116$ & $383 \pm 107$ & $p<0.05$ \\
Phosphate (mg) & $947 \pm 239$ & $804 \pm 154$ & $\mathrm{NS}$ \\
Protein (g) & $70.6 \pm 21.1$ & $58.7 \pm 9.5$ & $\mathrm{NS}$ \\
Fat (g) & $59.6 \pm 23.0^{\mathrm{a}}$ & $43.0 \pm 9.9 \mathrm{~b}$ & $p<0.05$ \\
Calorie (kcal) & $1,871 \pm 378$ & $1,559 \pm 265$ & $p<0.025$ \\
\hline
\end{tabular}

a $n=18$, b $n=12$. Mean \pm SD.

Table 2. Correlation coefficients between intake of calcium and that of calorie, protein, phosphate or fat.

\begin{tabular}{rrrrr}
\hline & Calorie & Protein & Phosphate & Fat \\
\hline$r$ & 0.491 & 0.619 & 0.734 & 0.535 \\
$p$ & $<0.001$ & $<0.001$ & $<0.001$ & $<0.001$ \\
\hline
\end{tabular}

$n=33$ except for fat $(n=30)$.

and B group ( $432 \pm 127 \mathrm{mg} / \mathrm{day}, n=7)$. Whereas the percentage of patients whose calcium intake exceeded $600 \mathrm{mg} /$ day counted $20.0 \%$ in group A, that in group B was $7.7 \%$. As for fat intake, no significant difference was observed in females, but it was higher in males of A group $(65.1 \pm 23.3 \mathrm{~g} /$ day, $n=7)$ than $\mathrm{B}$ group $(39.4 \pm 9.1 \mathrm{~g} /$ day, $n=6)$ $(p<0.05)$.

Correlation coefficients between intake of calcium and that of calorie $(r=0.491, p<0.001)$, protein $(r=0.619, p<0.001)$ and fat $(r=0.535, p<$ 0.001 ) were significant (Table 2, Fig. 1a and b).

2. Bone changes in hemodialysed patients with diabetic nephropathy. Regarding changes in the mandibular bones, the incidence of resorbed lamina dura and trabeculae of mandibular bones were significantly lower in hemodialysed diabetic patients than in hemodialysed non-diabetic patients (Table 3). Parathyroid hormone level was significantly lower in hemodialysed diabetic patients than in hemodialysed non-diabetic patients.

When hemodialysed diabetic patients were classified into 2 groups, depending on the level of hemoglobin $\mathrm{A}_{1}\left(\mathrm{HbA}_{1}\right)$, there were 12 patients whose $\mathrm{HbA}_{1}$ level was higher than $9.0 \%$ and 11 patients whose $\mathrm{HbA}_{1}$ level was lower than $9.0 \%$. There were no significant differences in serum
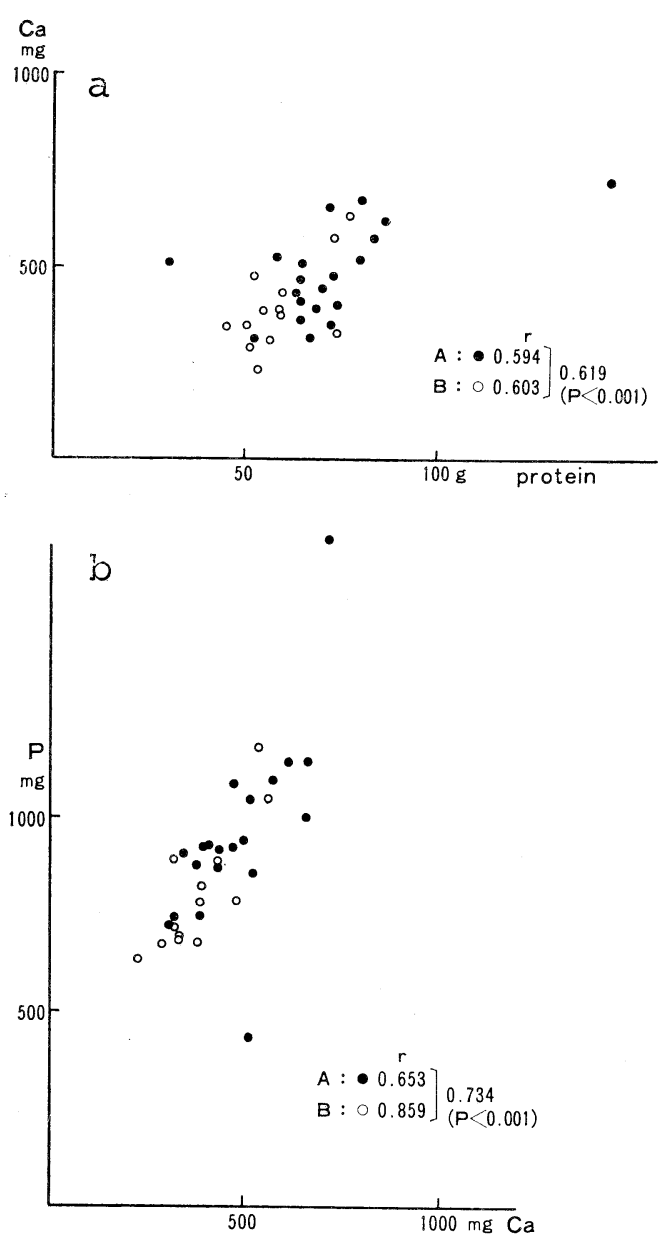

Fig. 1. Correlation between intakes of calcium and protein (a) or phosphate (b).

Table 3. Changes in lamina dura and trabecular patterns of jaw.

\begin{tabular}{lcccc}
\hline & None & Mild & Severe & Period(m) \\
\hline HD $\cdot$ DM & 8 & 1 & 0 & $34.7 \pm 4.0$ \\
HD · non DM & 14 & 6 & 13 & $35.6 \pm 4.8$ \\
\hline
\end{tabular}

$\chi^{2}$ test, $p<0.05$.

parathyroid hormone, AP, blood glucose, total protein, albumin and $\beta$-lipoprotein (Table 4).

No subperiosteal resorption of finger bones were observed in 23 hemodialysed patients with diabetic nephropathy.

The upper cortical width of clavicula was significantly lower in patients whose $\mathrm{HbA}_{\mathbf{1}}$ level was higher than $9.0 \%$ compared with patients 
Table 4. Comparison of biochemical data between the group with $\mathrm{HbA}_{1}$ level higher than $9 \%$ and that with $\mathrm{HbA}_{1}$ level lower than $9 \%$.

\begin{tabular}{lccc}
\hline & \multicolumn{3}{c}{$\mathrm{HbA}_{1}$} \\
\cline { 2 - 4 } & $9<(n=12)$ & $9>(n=11)$ & $p$ \\
\hline PTH $(\mathrm{ng} / \mathrm{ml})$ & $2.36 \pm 1.64$ & $2.14 \pm 1.38$ & NS \\
AP $(\mathrm{KAU})$ & $14.7 \pm 7.7$ & $17.1 \pm 9.0$ & $\mathrm{NS}$ \\
BG $(\mathrm{mg} / \mathrm{dl})$ & $208 \pm 82$ & $177 \pm 68$ & NS \\
TP $(\mathrm{g} / \mathrm{dl})$ & $6.90 \pm 0.58$ & $6.80 \pm 0.66$ & NS \\
Alb. $(\mathrm{g} / \mathrm{dl})$ & $4.00 \pm 0.31$ & $4.17 \pm 0.65$ & NS \\
$\beta$-Lipo. $(\mathrm{mg} / \mathrm{dl})$ & $436 \pm 185$ & $432 \pm 120$ & NS \\
\hline
\end{tabular}

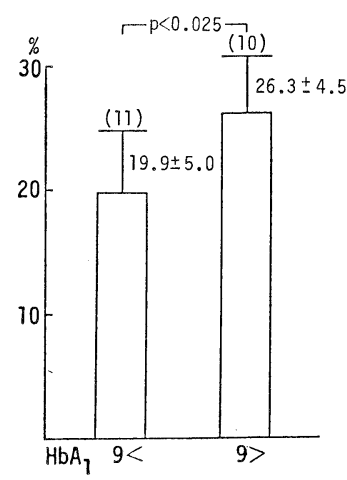

Fig. 2. Upper cortical width of clavicula in diabetic nephropathy.

whose $\mathrm{HbA}_{1}$ level was lower than $9.0 \%$ (Fig. 2). The clavicular score in 7 males of the $\mathrm{HbA}_{1}$ under 9 group, $25.1 \pm 5.0$, was again significantly higher than that in 8 males of the $\mathrm{HbA}_{1}$ over 9 group, $18.3 \pm 4.7(p<0.05)$.

\section{Discussion}

It has been demonstrated in the present investigation that nutritional factors, especially intakes of calcium, calorie and fat are important, so that active vitamin $\mathrm{D}$ has its effect on renal osteodystrophy. Although there was no significant difference in the intake of protein between good and poor response groups, as to the effect of active vitamin $\mathrm{D}$, the general improvement of nutritional status in patients with renal osteodystrophy would contribute to the improvement of bone changes. However, the intake of calcium, even in the good response group, was less than $500 \mathrm{mg}$. This value is lower than the recommended dietary allowance of Japan, $600 \mathrm{mg}$. Only $20 \%$ of patients in the good response group and $7.7 \%$ in the poor re- sponse group showed calcium intake of more than $600 \mathrm{mg}$.

Highly significant correlation coefficients between intakes of calcium and other nutrients may mean that the improvement of the general condition results in the increase of calcium intake. Although it is not known whether or not the higher intake of nutrients in the good response group is a cause or a result of improvement in abnormal calcium metabolism, a good cycle may be expected for the improvement of bone changes, even if the higher intake of nutrients is a result.

Diabetes mellitus is associated with osteopenia, in addition to other complications (l). However, bone changes, due to secondary hyperparathyroidism is not aggravated in hemodialysed patients with diabetic nephropathy (2). Bone changes estimated by the cortical thickness may reflect the grade of osteoporosis, rather than the grade of hyperparathyroidism. Since subperiosteal resorption of any degree of finger bones was not observed in both $\mathrm{HbA}_{1}$ over and under 9 groups, the control status of diabetes mellitus may not influence the grade of hyperparathyroidism, whereas no significant differences were demonstrated in levels of parathyroid hormone and alkaline phosphatase. Higher levels of cortical thickness in adequately treated patients with diabetic nephropathy suggest the direct or indirect beneficial effect of insulin.

\section{Summary}

1. Nutritional factors, especially calcium, calorie and fat intakes may be important in the treatment with active vitamin $D$, so that the effect appears more efficient. 2. Incidence of bone changes, due to hyper-parathyroidism in diabetic nephropathy, was less than that in non-diabetic patients under hemodialysis. 3. No effect of control status of diabetes mellitus was demonstrated, regarding incidence of subperiosteal resorption of finger bones. 4. Bone mass was decreased in diabetic patients in whom the control of blood glucose was inadequate.

\section{REFERENCES}

1) Levin, M.E. et al. (1976): N. Engl. J. Med., 294, 241.

2) Morii, H. et al. (1984): Nephron, 38, 22. 